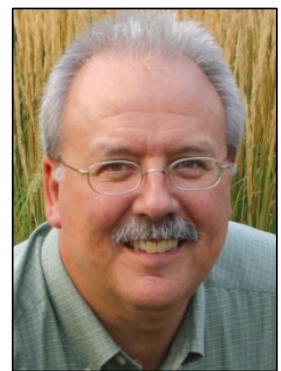

METRICS fROM THE FIELD

Blending insights from research with insights from practice

Ken Meter

\title{
Seventeen reasons to do food system assessments
}

Published online 30 November 2011

Citation: Meter, K. (2011, November). Seventeen reasons to do food system assessments. Journal of Agriculture, Food Systems, and Community Development, 2(1), 7-9. http://dx.doi.org/10.5304/jafscd.2011.021.014

Copyright (C) 2011 by New Leaf Associates, Inc.

If the purpose of a food system is to build health, wealth, connection, and capacity in our communities, then the process of assessing food systems should also contribute to those aims. Moreover, each food system assessment should be explicit about its approach to systemic analysis. Here are some detailed suggestions for why food system assessments should be compiled, and how they can better reflect core system dynamics.

Why do we compile food system assessments?

There are several solid answers to this question, of course: (1) Compiling a thorough set of measures of prevailing conditions helps establish an understanding of the baseline situation, which is useful for evaluating progress over time. (2) Without creating an explicit vision for a local or regional food system, it is very difficult to make (or measure) progress toward that vision. Compiling an assessment can help define such a vision. Further, (3) having one vision clearly articulated can help bring stakeholders together to work for a common purpose. Moreover, (4) it is deeply useful to consider the totality of the system, if possible. This helps (5) assure stakeholders that all of the major dynamics are in view, which may lead to more effective action. In addition, (6) by identifying central forces, pressure points, and contradictions within the system, local foods initiatives can more effectively set strategic priorities,

Ken Meter is president of Crossroads Resource Center in Minneapolis, Minnesota. He has performed 78 local food-system assessments in 30 states and one Canadian province; this information has promoted effective action in partner communities. He served as coordinator of the review process for USDA Community Food Project grants, and has taught economics at the Harvard Kennedy School and the University of Minnesota. He is co-convener of the Community Economic Development Committee of the Community Food Security Coalition. A member of the American Evaluation Association's Systems Technical Interest Group, Meter also serves as an Associate of the Human Systems Dynamics Institute. He serves as a contributing advisor to JAFSCD. 
(6) better understand how the system may resist efforts to change, and (7) better estimate how actions in one arena might impact stakeholders and issues in another. Many food leaders also point out that food system planning has so far been accomplished, by default, by private business interests who configured the system, and related public incentives, to maximize the profits of some key players in the system at the expense of others leading to immense imbalances of power and access. We need to plan, this argument goes, (9) to foster private/public collaboration to build food systems that achieve better outcomes and that broaden participation in planning so our food systems actually contribute to democracy.

All these replies strike me as true. Yet to me they also invite further questions at even greater depth: "What is the purpose of a food system?" and "Why do we call these food systems, anyway?"

To the first question, my response is that a sustainable food system will achieve four main purposes. It will build health, wealth, connection, and capacity in our communities (Meter, 2009). This seems common sense, yet the complexity of this purpose is often overlooked in the political fray.

I know farmers who feel that a food system is successful in any year in which they make good money - and not a subject for discussion when they do not. Other experts think the food system is working if farmers have access to the most advanced technologies available - whether farmers or consumers benefit from these technologies or not. I know people who consider a food system successful if its major businesses are large - but who overlook the fact that at the same moment, large portions of the population are not eating well. The importance of connecting culturally around food is often ignored in our food planning discussions. Seldom do I hear food planners raise the issue of building the capacity of consumers to hold the productive skills required to produce, prepare, and eat healthy foods.

Unfortunately, I see very smart people argue that the purpose of our work right now is to "go to scale," when in fact "going to scale" is a strategy, not a purpose. If scaling up fails to build health, wealth, connection, and capacity at the community level, it is the wrong strategy. This test, of course, should be applied to any strategy being contemplated.

My set of purposes is difficult to put forward amidst a political climate that is devoted to shortterm fixes. Part of the difficulty is that to assert this approach is to say that our purposes themselves are systemic - they cannot be boiled down to a single target. Our purposes interact with each other, and our ability to know how well we are progressing shifts daily. This is especially true now that so many people are diving into so much good work all at once. It is literally impossible to know all of what is happening.

I have already slipped into using systems language, which means I have entered the second of my two questions. Why do we call these food systems? Well, in part because what is going on is complicated, entangled, and not entirely knowable. Systems are not open to simple changes, because when one element of the system shifts, another force may resist, or reinforce, that change.

Some planners believe that if they put very systematic tables of measures, facts, and maps into a large document, then they have succeeded in holistically describing "the food system." This view suffers from the assumption that being systematic in one's analysis is the same as understanding the systemic forces at work. Rather, I have come to understand — with the help of many generous colleagues - that food systems are complex and adaptive (Meter, 2006). 
As I have argued in this column previously (Meter, 2010), the critical elements of food systems are changing rapidly, so what we measure this year may be less relevant next year. We need measures of emergence, and cannot afford to pretend the system sits still long enough for us to fully measure static facts. We must take measurements, and we must also understand their limits.

One of the complexities of systemic work is that the frames we use to analyze systems deeply impact what we see. If, for example, we view systems as predictable and static, we will tend to see those elements that might be considered stable, and may miss what is emerging. If we view systems as reducible to quantitative measures, we may only see those things than can accurately be counted, and may miss qualitative insights of deeper significance. If we focus on emergence, we may overlook more stable attributes.

The implication of this is that, as analysts, we need to be clear about the systems assumptions we make when we perform a food systems assessment, so we can help ourselves and our colleagues understand the potential strengths and blind spots of our own work. I am quite struck by how few analysts make their view of systems explicit, or even study systemic constructs enough to know there might be alternate frameworks that are useful for viewing a single system.

With this in mind, let me add to the list I offered at the start of this essay. The purpose of a food system assessment may also be (10) to build the capacities of local residents to understand, participate in, shape, and help evaluate their own food systems; (11) to ensure that cultural connections to food, and social connections among food system stakeholders, are strengthened; (12) to understand prevailing economic conditions affecting the food system, and the potential economic impacts of food system activity; (13) to become more clear about the assumptions we make when we address complex issues and systems; (14) to become more sophisticated in building our own systems frameworks so they more accurately reflect conditions on the ground as we move forward; (15) to capture insights into emergence, and how to effectively respond to changing conditions over time; and (16) to create transformative insights, including analysis of key "levers" that can move the system to a more sustainable place. Often all of this requires (17) giving voice to those who have been marginalized, since those on the margins - including lowincome residents, immigrants, and ethnic communities - often understand system dynamics more accurately than do those in more privileged positions, because they understand viscerally how the system pushes back.

If the purpose is to build health, wealth, connection, and capacity in communities, then the very process of assessing the food system must advance those aims. Having performed 78 food system assessments to date, both large and small, I understand the value of the large, comprehensive documents that are intended to reach policy makers (see Meter, 2012), but I am also aware of the small number of people who actually read such reports completely. I am quite persuaded that a relatively inexpensive but searching and honest analysis often has far more impact than the large tome - unless we are speaking strictly of the sound made when each document hits the floor when dropped from six feet in the air.

\section{References}

Meter, K. (2006). Evaluating farm and food systems in the U.S. In B. Williams \& I. Imam (Eds.), Systems concepts in evaluation: An expert anthology. [American Evaluation Association monograph]. Point Reyes, California: EdgePress of Inverness.

Meter, K. (2009, October). Mapping the Minnesota food industry. Minneapolis, Minnesota: Crossroads Resource Center. Available at http://www.crcworks.org/mnfood.pdf

Meter, K. (2010). Metrics from the field: Letting food systems emerge. Journal of Agriculture, Food Systems, and Community Development, 1(1), 23-25. http://dx.doi.org/10.5304/jafscd.2010.011.006

Meter, K. (2012). Hoosier farmer? Emerging food systems in Indiana. Indiana State Department of Health and Crossroads Resource Center. Will be available January 2012 at http://www.crcworks.org/ infood.pdf 
Journal of Agriculture, Food Systems, and Community Development ISSN: 2152-0801 online www.AgDevJournal.com 